\title{
Uso do teatro como ferramenta de ensino no curso técnico em agropecuária: um
}

\section{estudo de caso}

The using of theatre as a teaching tool in the technical course in agriculture: a case study

Uso del teatro como herramienta de enseñanza en el curso técnico en agricultura y ganadería: un estudio de caso

Recebido: 28/01/2021 | Revisado: 04/02/2021 | Aceito: 11/03/2021 | Publicado: 17/03/2021

Adriano Geraldo
ORCID: https://orcid.org/0000-0001-5342-6863
Instituto Federal de Educação, Ciência e Tecnologia de Minas Gerais, Brasil
E-mail: adriano.geraldo@ifmg.edu.br
Luiz Carlos Machado
ORCID: https://orcid.org/ 0000-0003-4126-9535
E-mail: luiz.machado@ifm, 1 .edu.br
Gustavo Augusto Lacorte
Instituto Federal de Educação, Ciência e Tecnologia de Minas Gerais, Brasil
ORCID: https://orcid.org/0000-0002-6866-348X
Instituto Federal de Educação, Ciência e Tecnologia de Minas Gerais, Brasil
E-mail: gustavo.lacorte@ifmg.edu.br

\begin{abstract}
Resumo
O ensino básico e técnico brasileiro é carente na aplicação de ferramentas educacionais alternativas para a obtenção de educação de excelência, que proporcione formação humana e cidadã. Dentre as várias alternativas lúdicas, se destaca a aplicação da técnica teatral, que oferece uma oportunidade para desinibição e desenvolvimento das virtudes como criatividade, resiliência, paciência, cooperação e proatividade. Este trabalho objetivou avaliar o uso do teatro na disciplina de Zootecnia I, oferecida aos estudantes do primeiro ano do curso técnico em Agropecuária do Instituto Federal de Educação, Ciência e Tecnologia de Minas Gerais - campus Bambuí e sua influência sobre o processo formativo. A metodologia foi aplicada para as turmas de 2017, 2018 e 2019 e avaliada através da aplicação de questionário eletrônico aos estudantes participantes, obtendo-se 34 respondentes. Considerando que a pontuação máxima da atividade era de 2,0 pontos, a nota média foi de 1,80 (90\% do valor total), o que revela comprometimento dos estudantes com a proposta. Contudo, uma parcela considerável (40\%) não compareceu à apresentação. De maneira geral, os estudantes avaliaram positivamente o teatro, principalmente no que se refere aos aspectos relacionados à timidez e concordaram que esta ferramenta foi importante para desenvolverem a criatividade, proatividade e cooperação. Assim, a metodologia do teatro pode ser um item significativo no processo de formação de sujeitos e proporcionar desenvolvimento de "soft skills", demanda crescente na atual sociedade 4.0.
\end{abstract}

Palavras-chave: Cooperação; Criatividade; Encenação no ensino; Metodologias alternativas; Metodologias lúdicas.

\begin{abstract}
Brazilian elementary and technical teaching is lacking of application of alternative educational tools for obtaining an excellent level of education, which provides human and citizen development. Among the various playful alternatives, the application of theatrical technique stands out, which offers an opportunity for disinhibition and development of virtues such as creativity, resilience, patience, cooperation and proactivity. This work aimed to evaluate the use of theatre in the discipline of Animal Science I, a signature offered to students in the first year of the technical course in Agriculture at the Federal Institute of Education, Science and Technology of Minas Gerais Bambuí campus, and its influence on the training process. The methodology was applied to the classes of 2017, 2018 and 2019 and evaluated through the application of an electronic questionnaire to the participating students, obtaining 34 respondents. Considering that the maximum score of the activity was 2.0 points, the average score was 1.80 (90\% of the total value), which reveals the students' commitment to the proposal. However, a considerable portion (40\%) did not attend the presentation. In general, the students positively evaluated the theatre, especially with regard to aspects related to shyness and agreed that this tool was important to develop creativity, proactivity and cooperation. Thus, the theatre methodology can be a significant item in the process of training subjects and provide the development of "soft skills", a growing demand in today's 4.0 society.
\end{abstract}

Keywords: Alternative technique; Cooperation; Creativity; Ludic technique; Staging in teaching. 


\begin{abstract}
Resumen
La enseñanza básica y técnica brasileña carece de la aplicación de herramientas educativas alternativas para la obtención de una educación de excelencia, que brinde desarrollo humano y ciudadano. Entre las diversas alternativas lúdicas, destaca la aplicación de la técnica teatral, que ofrece una oportunidad para la desinhibición y desarrollo de virtudes como la creatividad, la resiliencia, la paciencia, la cooperación y la proactividad. Este trabajo tuvo como objetivo evaluar el uso del teatro en la disciplina de Zootecnia I, ofrecido a los estudiantes del primer año del curso técnico en Agricultura y Ganaderia del Instituto Federal de Educación, Ciencia y Tecnología de Minas Gerais campus Bambuí y su influencia en el proceso de formación. La metodología se aplicó a las clases de 2017, 2018 y 2019 y se evaluó mediante la aplicación de un cuestionario electrónico a los estudiantes participantes, obteniendo 34 encuestados. Considerando que la puntuación máxima de la actividad fue de 2,0 puntos, la puntuación media fue de 1,80 (90\% del valor total), lo que revela el compromiso de los estudiantes con la propuesta. Sin embargo, una parte considerable (40\%) no asistió a la presentación. En general, los estudiantes evaluaron positivamente el teatro, especialmente en los aspectos relacionados con la timidez y coincidieron en que esta herramienta era importante para desarrollar la creatividad, la proactividad y la cooperación. Así, la metodología teatral puede ser un elemento significativo en el proceso de formación de las asignaturas y facilitar el desarrollo de las "soft skills", una demanda creciente en la actual sociedad 4.0.
\end{abstract}

Palabras clave: Cooperación; Creatividad; Didáctica en la enseñanza; Metodologías alternativas; Metodologías lúdicas.

\title{
1. Introdução
}

É de extrema importância que as escolas desenvolvam ferramentas adaptadas às suas especificidades, contribuindo para melhor elucidação de conteúdos técnicos ou de elevada complexidade. Além disso, devido à grande heterogeneidade no estilo de aprendizagem de cada estudante, o professor deverá variar as estratégias e criar alternativas que estejam relacionadas com atividades do cotidiano. O próprio Bruner postulavam que o conhecimento se desenvolvia por meio de uma relação entre estruturas mentais do sujeito e o ambiente externo, através de estímulos e vivências (Bruner, 1999; Goulart, 2009).

A educação de jovens envolve o desenvolvimento de virtudes e valores cruciais para a formação humana (MartínezPriego et al., 2014, Jiménez e Raméntol, 2018). Nesse contexto, o processo de ensino nas escolas pode ser de extrema importância para colaborar no desenvolvimento de virtudes como criatividade, resiliência, paciência, cooperação, proatividade, honestidade, amizade, temperança e perseverança. O professor deve atuar como agente transformador de vidas, no sentido em que deve proporcionar aos estudantes, oportunidades diversas, variadas e desafiadoras, para que desenvolvam suas virtudes e valores (Echeverría-Falla, 2013; Costa Lins e Souza, 2018; Jimenéz e Raméntol, 2018), não se tratando somente de conhecimento teórico e prático, mas sim de oportunidades para que o ensino seja transformado em educação de qualidade.

Iniciativas artísticas voltadas para o contexto educacional foram apresentadas por autores diversos em variadas áreas. $\mathrm{O}$ método body painting foi mais eficiente no aprendizado de estudantes de medicina quando comparado ao uso de peças anatômicas (Oliveira et al., 2020). Também na escola de medicina, o projeto "Mediarte com amor e humor" (Amorim et al., 2015) oportunizou aos estudantes a sua atuação em hospital pediátrico, a fim de lhes proporcionar atividades lúdico-recreativas com os pacientes, acompanhantes e equipe de saúde, proporcionando educação em saúde e desenvolvimento humano. Metodologias ativas foram utilizadas também na área de farmácia, onde Mattos et al. (2020) trabalharam avaliando a discussão sobre as práticas sanitárias e sua aplicabilidade na vida profissional, relatando que o seu uso possibilitou o acompanhamento da edificação dos saberes dos estudantes, demonstrando grande potencial para o desenvolvimento da aprendizagem, tornando-a ainda mais prazerosa. No ramo da pedagogia, Moraes e Lima (2019) trabalharam com artefatos digitais na formação de jovens estudantes, dentro dos novos conceitos de cibercultura, os quais estão intimamente relacionados ao dia a dia da juventude moderna.

As relações entre teatro e educação são discutidas e exploradas desde a Antiguidade. O contexto histórico de cada época influenciou as diferentes práticas pedagógicas e a diversidade de maneiras de se pensar o drama em contextos educativos. A visão histórica indica que o teatro quase sempre foi concebido como um excelente aliado à educação, por mais 
distintas que fossem as épocas e mais diversos os objetivos pedagógicos (Hansted e Gohn, 2013). O ensino de ciências associado à arte, através do uso do teatro, pode constituir uma potente ferramenta para recriação de cenas e conceitos científicos, pois proporciona ações reflexivas, formativas e educativas, podendo atuar de maneira significativa na formação de cidadãos críticos. Além disso, esta ferramenta também pode colaborar para desenvolvimento de faculdades relacionadas à colaboração mútua, respeito ao próximo e disciplina (Hansted e Gohn; 2013; Coelho, 2014; Graça e Gonçalves, 2014; Sanfelice e Meinerz, 2017; Freitas e Gonçalves, 2018, Silva Júnior et al., 2018). No Brasil, o teatro na educação é ainda pouco explorado pelas escolas, sendo uma atividade pedagógica com ampla capacidade de inclusão e socialização dos alunos no ambiente escolar.

Percebe-se que quase não há trabalhos sobre alternativas lúdicas voltados para o ensino médio e profissionalizante, sendo esta carência preocupante, haja vista a fase psicológica que estes estudantes estão inseridos. Dessa maneira, este trabalho objetivou descrever e avaliar a aplicação da metodologia de teatro aos recém ingressantes no curso técnico em Agropecuária integrado ao ensino médio, avaliando sua percepção sobre as melhorias na criatividade, cooperação, paciência, proatividade e resiliência, além de propor ajustes para implementação em turmas futuras.

\section{Metodologia}

Este trabalho foi desenvolvido na disciplina de Zootecnia I que aborda conteúdos técnicos na área de Avicultura e Piscicultura, ministrada aos estudantes do primeiro ano do curso Técnico em Agropecuária Integrado ao ensino médio do IFMG campus Bambuí. Para este estudo, foram utilizadas três turmas que cursaram a disciplina nos anos de 2017, 2018 e 2019. Esta pesquisa foi previamente aprovada por comitê de ética (CAAE 32770820.4.0000.5113).

No início do primeiro semestre letivo de cada ano, foi apresentado a todos os estudantes o plano de ensino da disciplina contendo todas as atividades avaliativas referentes ao conteúdo de avicultura. Para a atividade referente ao teatro em avicultura, considerando que as turmas eram compostas por aproximadamente 32 alunos, foi proposta a formação de seis grupos de trabalho, com, no máximo, seis estudantes por grupo. Por questões de afinidade, facilidade de diálogo e deslocamento para reuniões para elaboração da atividade, os estudantes tiveram a liberdade de escolha de membros para formarem seus grupos de trabalho. Após a definição dos grupos, os temas previamente definidos no plano de ensino foram distribuídos através de sorteio. Foi utilizado como material básico o livro "Produção e Manejo de Frangos de Corte" de Albino e Tavernari (2008), onde se utilizou para a elaboração do teatro o capítulo "Criação de frangos de corte", dividindo-se em trechos para cada um dos grupos, sendo este material disponibilizado via e-mail, sistema acadêmico e também na forma de livros físicos disponíveis na biblioteca.

No mesmo dia do sorteio dos temas, foram também apresentados aos estudantes os motivos para a realização desta atividade avaliativa. Dentre as habilidades trabalhadas destacam-se a capacidade de síntese, desinibição, trabalho em equipe, ampliação do universo artístico e cultural, dando-se ênfase também ao estímulo à criatividade, e consequentemente a formação de um ser humano consciente de suas diversas competências (Coelho, 2014). Ainda neste encontro, foram apresentadas as regras para elaboração e apresentação do trabalho, sendo sumarizadas no Quadro 1. 
Quadro 1. Regras para apresentação do trabalho teatral por alunos do primeiro ano do curso técnico integrado em Agropecuária do IFMG - campus Bambuí, na disciplina de Zootecnia I.

\begin{tabular}{|c|c|}
\hline Área & Regras adotadas \\
\hline Organização do esquete & $\begin{array}{l}\text { 1. Este esquete teatral deve ser ajustado ao conteúdo do texto técnico pertinente } \\
\text { ao respectivo grupo, podendo-se utilizar dos estilos comédia, tragédia, } \\
\text { apresentação de telejornal, entrevista, etc. } \\
\text { 2. Todos os estudantes devem participar da atividade, sejam como protagonistas } \\
\text { ou coadjuvantes, sendo importante a expressão verbal de cada integrante, } \\
\text { mesmo que por curto espaço de tempo. } \\
\text { 3. O tempo máximo de apresentação é de sete minutos, havendo mais quatro } \\
\text { minutos para posterior debate e até cinco minutos para desmontagem do cenário } \\
\text { anterior e montagem do seguinte. } \\
\text { 4. O professor está disponível para sanar as dúvidas pertinentes ao texto a ser } \\
\text { apresentado, desde que agendado previamente para atendimento presencial na } \\
\text { sala do docente ou atendimento por meio de correio eletrônico. }\end{array}$ \\
\hline $\mathrm{Ma}$ & $\begin{array}{l}\text { 1. Estão disponíveis materiais e equipamentos para uso dos estudantes, tais } \\
\text { como, aparelho projetor multimídia (Datashow), microcomputador portátil, } \\
\text { quadro branco para anotações, pincel para quadro branco, mesas e carteiras de } \\
\text { uso diário em sala de aula. } \\
\text { 2. Os estudantes devem procurar previamente o técnico responsável pelo } \\
\text { laboratório de avicultura, afim de solicitar o empréstimo de materiais e } \\
\text { equipamentos de uso no setor produtivo, tais como material de cama de frango, } \\
\text { pá, rastelo, chapa para confecção dos círculos de proteção, bebedouro tipo copo } \\
\text { de pressão, bebedouro pendular, comedouro tubular e campânula para } \\
\text { aquecimento. } \\
\text { 3. Animais vivos podem ser utilizados durante a encenação, ficando a aquisição, } \\
\text { manutenção e fornecimento de alimentos sob responsabilidade de cada grupo. } \\
\text { Por questões de biosseguridade, a instituição não disponibilizou as aves. } \\
\text { 4. Outros materiais como chapéu, bota e roupas podem ser utilizados no } \\
\text { figurino ou cenário. }\end{array}$ \\
\hline Local da apresentação & $\begin{array}{l}\text { 1. A atividade é realizada em sala de aula, utilizando a parte da frente da sala, } \\
\text { onde se localiza o quadro negro. Para se ter espaço suficiente, pode se afastar a } \\
\text { mesa do professor para um canto da sala e se retirar as duas primeiras fileiras de } \\
\text { carteiras. }\end{array}$ \\
\hline $\begin{array}{l}\text { Atividades } \\
\text { apresentação } \\
\text { encerramento }\end{array}$ & $\begin{array}{l}\text { 1. Após a apresentação, os integrantes devem se reunir na frente da turma para } \\
\text { exposição de pontos técnicos essenciais, ressaltando sua importância dentro da } \\
\text { avicultura. } \\
\text { 2. Para encerrar a atividade, cada grupo deve realizar a limpeza da sala bem } \\
\text { como entregar os materiais tomados previamente. }\end{array}$ \\
\hline
\end{tabular}


Os critérios avaliativos adotados para o trabalho e seus percentuais (pesos) para o cálculo da nota final foram: colaboração mútua (40\%), criatividade (30\%) e domínio do tema apresentado $(30 \%)$. As atividades realizadas pelo docente previamente a apresentação são apresentadas no Quadro 2. Destaca-se que a colaboração do professor neste processo formativo é fundamental, haja vista que a maioria dos estudantes do curso técnico em agropecuária nunca passou por situações semelhantes antes. Ressalta-se que a ação descrita no parágrafo anterior foi fundamental para que grupos que demonstravam pouca iniciativa durante o período preparatório pudessem iniciar seus trabalhos, bem como para lhes ressaltar a importância da colaboração individual e mútua entre os membros.

Quadro 2. Ações prévias do professor para maior elucidação da apresentação dos estudantes no esquete teatral.

\begin{tabular}{|c|c|}
\hline Área & Ações do professor \\
\hline Orientação dos & $\begin{array}{l}\text { 1. Esclarecimento de dúvidas de ordem técnica } \\
\text { 2. Orientações sobre as possíveis modalidades para apresentação, } \\
\text { principalmente buscando-se desenvolver a criatividade. }\end{array}$ \\
\hline $\begin{array}{l}\text { Aspectos ligados à } \\
\text { interpretação }\end{array}$ & $\begin{array}{l}\text { 1. Apresentação de pontos essenciais para se lograr boa qualidade de } \\
\text { apresentação, destacando-se aspectos de aparência, apresentação pessoal, } \\
\text { movimento e gesticulação das mãos, atenção direta e visual ao público ouvinte, } \\
\text { uso do vocabulário correto, uso de gírias e expressões idiomáticas, etc. } \\
\text { 2. Esclarecimento sobre possíveis ajustes, haja vistas que dependendo do estilo } \\
\text { de apresentação (por exemplo comédia), haveria a necessidade de mudanças, } \\
\text { onde algumas normas poderiam ser reajustadas. Como exemplo, usou-se a } \\
\text { figura do personagem Jeca Tatu, que se utiliza de um português incorreto. }\end{array}$ \\
\hline Aspectos ligados aos slides & $\begin{array}{l}\text { 1. Orientação sobre a elaboração de slides relacionadas ao tipo e cor do fundo } \\
\text { utilizado, importância do contraste entre letras e fundo, tamanho da fonte, } \\
\text { utilização de fotos e esquemas para tornar a apresentação mais atrativa, } \\
\text { importância de se trabalhar informações diretas e em boa quantidade, etc. } \\
\text { 2. Enfatizou-se que esta apresentação em slides era somente um roteiro e que } \\
\text { seria necessário uma apresentação prévia, interna ao grupo, para maior } \\
\text { elucidação do conteúdo e treinamento da equipe. }\end{array}$ \\
\hline
\end{tabular}

Fonte: Autores.

No período de julho a agosto de 2020 o questionário foi enviado aos ex-alunos da disciplina, através de um link, via plataforma Google Formulários (Quadro 3) que tinha como intuito verificar o impacto desta metodologia sobre a formação do estudante. Foram considerados aptos para responderem somente aqueles que participaram da atividade avaliativa descrita nesta metodologia, excluindo os alunos que se ausentaram da apresentação. A utilização de questionários on line é uma importante ferramenta para melhoria no processo de ensino-aprendizado (Marques, 2011), sendo potencializada e ganhando maior eminência no período de pandemia. Foram respondidos um total de 34 questionários, havendo 12, 10 e 12 para as turmas de 2017, 2018 e 2019, respectivamente. Neste sentido verifica-se que foram alcançados 70,0\%, 45,5\% e 57,1\% dos estudantes que realizaram esta atividade no devido ano. O formulário base utilizado é apresentado no Quadro 3. 
Quadro 3. Formulário para avaliação do impacto da metodologia teatral sobre a formação de alunos do curso técnico em Agropecuária integrado ao ensino médio.

\begin{tabular}{|c|c|}
\hline Descrição da pergunta & Opções para marcação \\
\hline $\begin{array}{l}\text { Termo de Consentimento: Caro estudante ou ex-estudante do } \\
\text { curso técnico em agropecuária, você está sendo convidado a } \\
\text { participar de uma pesquisa sobre uma metodologia usada na } \\
\text { disciplina de avicultura, intitulada: Uso do teatro em sala de } \\
\text { aula para ensino. Todos os participantes desta pesquisa } \\
\text { cursaram e a disciplina entre os anos de } 2017 \text { a } 2019 \text { e fizeram o } \\
\text { trabalho. O questionário será aplicado através deste formulário } \\
\text { eletrônico, enviado para seu e-mail ou número de celular } \\
\text { pessoal. A pesquisa terá como objetivos principais: identificar } \\
\text { nas estudantes melhorias nos aspectos de desinibição, } \\
\text { cooperação, criatividade, proatividade e paciência, além de } \\
\text { possível melhorias para a metodologia. Pedimos bastante } \\
\text { sinceridade para responder ao questionário. A média dos } \\
\text { resultados será utilizada em trabalho científico a ser publicado, } \\
\text { bem como os comentários individuais. Não haverá qualquer tipo } \\
\text { de identificação dos questionários e respostas }\end{array}$ & ( ) Li e aceito o termo de consentimento \\
\hline Sexo & $\begin{array}{l}\text { ( ) Homem } \\
\text { ( ) Mulher } \\
\text { ( ) Outro }\end{array}$ \\
\hline Situação do(a) ex-aluno(a): & $\begin{array}{l}\text { ( ) Fiz a disciplina há um ano, em } 2019 . \\
\text { ( ) Fiz a disciplina há dois anos, em } 2018 . \\
\text { ( ) Fiz a disciplina há três anos, em } 2017 .\end{array}$ \\
\hline Você foi aprovado na disciplina de avicultura? & $\begin{array}{l}\text { ( ) Sim, fui aprovado na primeira vez. } \\
\text { ( ) Fui reprovado no primeiro ano que cursei, mas } \\
\text { logo passei posteriormente. } \\
\text { ( ) Não fui aprovado ainda. }\end{array}$ \\
\hline Sobre a timidez: & $\begin{array}{l}\text { ( ) Eu era uma pessoa tímida naquela época e } \\
\text { estou trabalhando nisso. } \\
\text { ( ) Eu era e ainda sou uma pessoa tímida. } \\
\text { ( ) Nunca fui uma pessoa tímida. }\end{array}$ \\
\hline $\begin{array}{l}\text { Onde você residia no período anterior à disciplina de avicultura } \\
\text { (considere a maior parte do tempo)? }\end{array}$ & $\begin{array}{l}\text { ( ) Zona rural. } \\
\text { ( ) Zona urbana. }\end{array}$ \\
\hline $\begin{array}{l}\text { As questões a seguir, deverão ser respondidas de acordo com o } \\
\text { seu grau de satisfação com a apresentação do teatro na } \\
\text { disciplina de avicultura, bem como o quanto você acredita que } \\
\text { ela acrescentou em sua formação. }\end{array}$ & ( ) Entendi. \\
\hline Acredito que esta metodologia do teatro me ajudou a apresentar & ( ) Concordo plenamente. \\
\hline
\end{tabular}




\begin{tabular}{|c|c|}
\hline $\begin{array}{l}\text { trabalhos com mais facilidade nas demais disciplinas e no } \\
\text { estágio final obrigatório. }\end{array}$ & $\begin{array}{l}\text { ( ) Sim, acrescentou em minha formação. } \\
\text { ( ) Provável que sim.. } \\
\text { ( ) Talvez isso tenha acontecido, mas não tenho } \\
\text { certeza } \\
\text { ( ) Não concordo. } \\
\text { ( ) Não consigo responder a esta questão. }\end{array}$ \\
\hline $\begin{array}{l}\text { O tempo de três semanas oferecido pelo professor para a } \\
\text { elaboração do trabalho foi suficiente. }\end{array}$ & $\begin{array}{l}\text { ( ) Concordo plenamente. } \\
\text { ( ) Sim, deu pra trabalhar. } \\
\text { ( ) Provável que sim. } \\
\text { ( ) Talvez isso tenha acontecido, mas não tenho } \\
\text { certeza. } \\
\text { ( ) Não concordo. } \\
\text { ( ) Não consigo responder a esta questão. }\end{array}$ \\
\hline $\begin{array}{l}\text { Sobre o conteúdo do trabalho, eu aprendi mais com o teatro do } \\
\text { que se eu tivesse estudado somente da forma tradicional. }\end{array}$ & $\begin{array}{l}\text { ( ) Concordo plenamente. } \\
\text { ( ) Sim, eu aprendi muito da matéria a partir do } \\
\text { teatro. } \\
\text { ( ) Provável que sim. } \\
\text { ( ) Talvez isso tenha acontecido, mas não tenho } \\
\text { certeza. } \\
\text { ( ) Não concordo. } \\
\text { ( ) Não consigo responder a esta questão. }\end{array}$ \\
\hline $\begin{array}{l}\text { O material fornecido pelo professor (Datashow, computador, } \\
\text { quadro e pincel) bem como os materiais e equipamentos do } \\
\text { laboratório de avicultura (material de cama de frango, pá, } \\
\text { rastelo, chapa para confecção dos círculos de proteção, } \\
\text { comedouro, bebedouros tipo copo de pressão, bebedouros } \\
\text { pendulares, comedouros tubulares, campânulas) foram } \\
\text { suficientes para que nosso grupo elaborasse um trabalho criativo } \\
\text { e de boa qualidade. }\end{array}$ & $\begin{array}{l}\text { ( ) Concordo plenamente. } \\
\text { ( ) Sim, acrescentou em minha formação. } \\
\text { ( ) Provável que sim. } \\
\text { ( ) Talvez isso tenha acontecido, mas não tenho } \\
\text { certeza. } \\
\text { ( ) Não concordo. } \\
\text { ( ) Não consigo responder a esta questão. }\end{array}$ \\
\hline $\begin{array}{l}\text { Inicialmente antes da apresentação do teatro o professor } \\
\text { apresentou a metodologia de como preparar apresentações, } \\
\text { como se portar e falar em público. Acredito então que essa ação } \\
\text { foi importante para que eu melhorasse minha capacidade de } \\
\text { falar em público. }\end{array}$ & $\begin{array}{l}\text { ( ) Concordo plenamente. } \\
\text { ( ) Sim, acrescentou em minha capacidade de } \\
\text { falar em público. } \\
\text { ( ) Provável que sim. } \\
\text { ( ) Talvez isso tenha acontecido, mas não tenho } \\
\text { certeza. } \\
\text { ( ) Não concordo. } \\
\text { ( ) Não consigo responder a esta questão. }\end{array}$ \\
\hline $\begin{array}{l}\text { No início eu achei o trabalho do teatro complexo, mas aos } \\
\text { poucos fui me interessando pelo trabalho e ao final gostei muito }\end{array}$ & $\begin{array}{l}\text { ( ) Concordo plenamente. } \\
\text { ( ) Sim, ao final eu gostei e achei interessante. }\end{array}$ \\
\hline
\end{tabular}




\begin{tabular}{|c|c|}
\hline da iniciativa. & $\begin{array}{l}\text { ( ) Provável que sim. } \\
\text { ( ) Talvez isso tenha acontecido, mas não tenho } \\
\text { certeza. } \\
\text { ( ) Não concordo. } \\
\text { ( ) Não consigo responder a esta questão. }\end{array}$ \\
\hline $\begin{array}{l}\text { A pontuação atribuída ao trabalho ( } 2 \text { pontos) foi suficiente e a } \\
\text { maior parte dos estudantes se mostrou interessada em obter } \\
\text { estes pontos. }\end{array}$ & $\begin{array}{l}\text { ( ) Concordo plenamente. } \\
\text { ( ) Sim, ao final eu vi que esta pontuação foi justa. } \\
\text { ( ) Provável que sim. } \\
\text { ( ) Talvez isso tenha acontecido, mas não tenho } \\
\text { certeza. } \\
\text { ( ) Não concordo. } \\
\text { ( ) Não consigo responder a esta questão. }\end{array}$ \\
\hline $\begin{array}{l}\text { Como foi o grau de cooperação com os colegas durante a } \\
\text { elaboração e execução dos trabalhos? }\end{array}$ & $\begin{array}{l}\text { ( ) Equilibramos bem a divisão de tarefas e assim } \\
\text { cada um fez sua parte. } \\
\text { ( ) Equilibramos bem a divisão mas ao final } \\
\text { alguns colegas trabalharam menos. } \\
\text { ( ) Ao final alguns colegas ficaram mais } \\
\text { sobrecarregados que outros. } \\
\text { ( ) Eu fiz o trabalho quase sozinho. } \\
\text { ( ) Não fiz nada e os outros fizeram por mim. } \\
\text { ( ) Não consigo responder a esta questão }\end{array}$ \\
\hline $\begin{array}{l}\text { Como foi o seu grau de interesse pelas apresentações dos } \\
\text { grupos? }\end{array}$ & $\begin{array}{l}\text { ( ) Me interessou muito e prestei bastante atenção } \\
\text { em todas as apresentações. } \\
\text { ( ) Me interessou um pouco e assisti às } \\
\text { apresentações. } \\
\text { ( ) Pra mim tanto faz. } \\
\text { ( ) Indiferente, somente assisti por obrigação. } \\
\text { ( ) Não me interessei pelos trabalhos dos colegas. } \\
\text { ( ) Não consigo responder a esta questão. }\end{array}$ \\
\hline $\begin{array}{l}\text { A seguir coloque um valor entre } 1 \text { e } 5 \text { para o grau de cada uma } \\
\text { das virtudes desenvolvidas por você durante a elaboração e } \\
\text { apresentação do trabalho em forma de teatro. Exemplo: se } \\
\text { acredito que o trabalho apresentado em forma de teatro } \\
\text { melhorou muito minha criatividade, posso dar nota } 4 \text { ou } 5 \text {. Caso } \\
\text { eu acredite que não melhorou nada, ou melhorou pouco, posso } \\
\text { dar nota } 1 \text { ou } 2 \text {. }\end{array}$ & ( ) Entendi. \\
\hline Criatividade: & $(1$ a 5$)$ \\
\hline Cooperação: & $(1$ a 5$)$ \\
\hline Paciência: & $\ldots(1$ a 5$)$ \\
\hline
\end{tabular}




\begin{tabular}{|l|c|}
\hline $\begin{array}{l}\text { Proatividade (capacidade de tomar iniciativas por conta } \\
\text { própria): }\end{array}$ & (1 a 5) \\
\hline Resiliência (capacidade de aceitar problemas e fracassos sem & \multirow{2}{\text{deixarqueissoatrapalheoseudesenvolvimento):}}{ (1 a 5) } \\
\hline $\begin{array}{l}\text { Para finalizar, escreva um breve depoimento sobre o que você } \\
\text { achou (pontos positivos e/ou negativos) do uso da apresentação } \\
\text { em forma de teatro na disciplina de Avicultura (esta sua opinião } \\
\text { é importante para aplicação desta metodologia do teatro em } \\
\text { outras turmas do curso técnico integrado) }\end{array}$ & \\
\hline
\end{tabular}

Fonte: Autores.

Após a coleta dos dados, os mesmos foram transformados em médias, sendo as mesmas analisadas descritivamente.

\section{Resultados e Discussão}

\section{(i) Avaliação dos questionários}

O desempenho dos alunos que realizaram esta atividade foi bastante satisfatório. Dos dois pontos distribuídos, estudantes das turmas de 2017, 2018 e 2019 alcançaram os valores médios de 1,90; 1,67 e 1,82 pontos, respectivamente, para a atividade realizada. Porém, chamamos a atenção para a ausência de 55,00\%, 31,25\% e 34,37\% dos alunos das turmas supracitadas, respectivamente, na realização da atividade. Nota-se que uma maior evasão nesta atividade está de alguma maneira correlacionada com a seleção dos estudantes matriculados na disciplina. Os participantes normalmente têm maior nível de comprometimento e alcançam maiores notas.

Esta elevada evasão é preocupante, sendo necessário se buscar alternativas para redução desta taxa. Uma possibilidade seria de se incrementar o diálogo com as turmas futuras e se enfatizar a importância desta atividade para a formação pessoal e desenvolvimento de virtudes correlacionadas, sendo este papel muito importante e complexo dentro da atual carreira docente (Fuhr, 2020). Nota-se que este maior nível de diálogo pode ter favorecido uma participação mais ampla dos estudantes, comparando-se os anos de 2017 e 2018 . Tal melhoria não é observada no ano seguinte, sugerindo que pode haver um limite no interesse da turma ou ainda a necessidade de outras formas de atuação. Neste sentido, outra ação crucial poderia estar relacionada a atribuição de uma pontuação maior, visando despertar maior interesse nos estudantes. Houve vários relatos, e alguns destes destacaram o valor da pontuação, como descrito a seguir e que também será melhor detalhado posteriormente. Chama atenção o fato do estudante ter-se confundido quanto ao período em que a atividade foi aplicada, pois é sempre no início da disciplina, por volta de um mês e meio após o início das aulas.

“É importante o uso desde método, pois no primeiro ano do curso os alunos ainda estão tímidos, ou com medo dos colegas novos e da escola, e essa é uma forma divertida de aprender. Mas há um desinteresse muito grande em fazer algo assim, talvez porque o trabalho foi aplicado no final do ano onde a maioria já conseguiu média, ou sendo apenas 2 pontos, e também por causa dessa timidez.” (Aluna da turma de 2017)

É importante se destacar que após as apresentações, os discentes comentavam sobre o conteúdo abordado e alguns riam das colocações técnicas apresentadas no teatro, principalmente aquelas que estavam em desacordo com a correta abordagem do assunto. Em relação à parte artística, observou-se bastante criatividade por parte dos estudantes para montagem 
do cenário, facilitando de certa maneira, o rompimento da timidez e fortalecendo a capacidade de iniciativa de cada grupo. Deve-se considerar aqui que estudantes advindos da zona rural normalmente são mais tímidos e na maioria das vezes não tiveram contato algum com a metodologia do teatro, a qual pode ser fundamental para despertar o lado artístico e lúdico presente em cada um, além de trabalhar a timidez enfrentada pela maioria dos jovens.

A maioria dos entrevistados foi composta por homens $(61,8 \%)$. Embora ainda sejam a minoria, nota-se, a partir da prática docente do dia a dia, que nos últimos anos tem havido um considerável crescimento no público feminino que busca o curso técnico em Agropecuária. Dos entrevistados, um total de 29 estudantes (85,3\%) foram aprovados na disciplina de Zootecnia I (Avicultura e Piscicultura).

Sobre a origem, 28 estudantes $(82,4 \%)$ responderam que vieram do meio urbano, o que sugere uma mudança na origem destes alunos, os quais nas décadas anteriores, vinham, em sua maioria, tradicionalmente da zona rural. Esta situação é confirmada a partir das observações do dia-a-dia da sala de aula a partir do diálogo com os estudantes, considerando-se principalmente os últimos 15 anos, corroborando com a tendência de incremento da população urbana (IBGE, 2016).

Em relação à timidez, uma parcela considerável dos estudantes que adentram o curso técnico em Agropecuária tem alguma dificuldade para expressão ou relacionamento, principalmente no primeiro ano. Isso é confirmado pelo fato de que 20 estudantes $(58,8 \%)$ responderam que eram tímidos naquela época em que iniciaram o curso e que ainda estão trabalhando nesta questão. Soma-se a este montante os quatro estudantes $(11,8 \%)$ que relataram que ainda são pessoas tímidas. Dessa maneira, verifica-se que mais de $2 / 3$ dos estudantes reconheciam que tinham certo nível de timidez, estando esta situação extremamente relacionada com a idade destes jovens, havendo posterior amadurecimento emocional e, por conseguinte, desinibição. Situação semelhante também foi relatada por Gonçalves e Sestari (2015). De qualquer forma, os dados apontam para a necessidade de técnicas como estas serem aplicadas logo no primeiro ano de alunos do curso técnico em Agropecuária. Alguns relatos descreveram como esta metodologia de teatro os ajudou na interação da turma, sendo um exemplo apresentado a seguir.

\footnotetext{
"Me ajudou muito a conseguir conversar com outras pessoas pois sou uma pessoa muito tímida e tenho dificuldades em apresentar trabalhos na frente de muitas pessoas, mas hoje eu já consigo me relacionar melhor com o público, até porque hoje eu trabalho e no meu emprego eu tenho que dialogar com as pessoas e isso me ajudou muito. " (Aluno da turma de 2017).
}

Deve ser enfatizado que alternativas que trabalhem a timidez dos alunos devem ter prioridade no processo de ensino. Conforme destacado por Gonçalves e Sestari (2015), a timidez pode favorecer o aparecimento de desconforto, medo, angústias e retroação social, devendo o assunto ser merecedor de maior atenção por parte da escola.

Considerando que uma parcela considerável dos estudantes do primeiro ano é extremamente tímida, o professor deve dialogar sobre a importância de se trabalhar aspectos de oratória, estar disponível para sanar as várias dúvidas que surgem, bem como identificar possíveis grupos desconsoantes. Ao questionar os estudantes sobre esta preparação, $85,3 \%$ acreditavam que a mesma havia auxiliado na sua capacidade de falar em público. Nota-se que os estudantes do primeiro ano vivenciam um período de grandes transformações em esferas diversas, sendo o diálogo ferramenta fundamental para formação de seu caráter. Ainda nesta linha, o estudante deve ter a percepção de que todo o trabalho tem como objetivo o desenvolvimento de virtudes pessoais e assim, $82,4 \%$ dos estudantes disseram haver gostado desta iniciativa.

O teatro de encenação, por ser uma necessidade essencial do ser humano (Vigotski, 2001), é um meio propício não somente às interações sociais, mas a resultados que são produzidos em concomitância e/ou a posteriori. Conforme relatado por Francisco Júnior et al. (2014) a contradição de emoções, que se configurou desde os momentos preparativos do teatro por 
alunos do PIBID até a apresentação, levou alguns estudantes a encarar e superar sentimentos como a timidez, a inibição de falar em público, a ansiedade e o anseio de promover algo inovador.

A grande maioria $(70,6 \%)$ dos entrevistados acreditam que a metodologia de teatro contribuiu para melhorar sua capacidade de apresentar trabalhos, sendo este retorno fundamental, pois sugere que os alunos foram receptivos para adoção desta metodologia, mesmo que esta esteja valendo poucos pontos. Também Carvalho e Novo (2014) destacaram que a adaptação dos adolescentes em diferentes contextos da vida, está associada a uma evolução da sua personalidade, considerando seu maior nível de desinibição e emocionalidade positiva.

\footnotetext{
"A elaboração do trabalho pode ser complexa para alguns grupos devido a estarem no primeiro ano e talvez não possuírem um entrosamento sólido além de uma estratégia formada para a construção do trabalho, porém, o trabalho se mostra muito útil para o crescimento escolar, uma vez que auxilia nestes quesitos e serve para o melhoramento de postura em atividades de apresentação como seminários, discursos, defesas e etc. Além de ser bastante divertido no momento da apresentação, tanto para o grupo como para a turma." (Aluno da turma de 2017)
}

Sobre o tempo de três semanas para preparo da apresentação, a grande maioria $(85,3 \%)$ acredita que o tempo foi suficiente para a preparação. Contudo, a prática pedagógica do dia-a-dia mostra que a maior parte dos estudantes realiza as atividades preparatórias nos dias que antecedem a apresentação do trabalho acadêmico, sendo isso observado a partir da percepção de maior agitação e movimentação por parte dos estudantes bem como maior buscar para esclarecimento de dúvidas.

A maioria $(73,5 \%)$ dos entrevistados disseram acreditar que aprenderam mais a partir da técnica do teatro quando comparado à metodologia tradicional, onde o professor explica o conteúdo ao aluno e depois o trabalha na forma de avaliação. Isto pode ser visualizado a partir dos relatos a seguir:

"A atividade proposta pelo professor faz com que seja mais fácil o aprendizado da matéria, já que quase todos os professores vão para o lado convencional, inovar e propor atividades diferentes faz com que aprender seja mais fácil e mais interessante." (Aluno da turma de 2019).

"Gostei bastante do trabalho, pude interagir com toda a turma, aumentou a capacidade de comunicação, ampliou as formas de ensino. Observei vários pontos positivos, como: melhor forma de aprendizagem, todos os alunos participaram de alguma forma e isso fez com que a sala toda interagisse, etc.” (Aluna da turma de 2017).

A metodologia tradicional é atualmente muito questionada, pois de maneira mecanicista, objetiva "colocar conteúdo na cabeça dos estudantes", os quais normalmente somente estudam o suficiente para atingirem a pontuação mínima exigida. Sabe-se que grande parte deste conhecimento será esquecido já no semestre seguinte, principalmente se não for utilizado em alguma disciplina posterior. Neste sentido, os métodos alternativos são de extrema importância para desenvolvimento cognitivo, atendendo também a estudantes que possuem estilos de aprendizagem diferenciados.

Nesta temática, Junqueira et al. (2002) relataram que o teatro na escola tem uma importância fundamental na promoção da educação, por oportunizar aos estudantes uma enorme gama de aprendizados ligados à socialização, criatividade, coordenação, memorização, ampliação de vocabulário e muitas outras habilidades e competências. Outros resultados positivos foram também verificados por Francisco Júnior et al. (2014); Sanfelice e Meinerz (2017) e Silva Júnior et al. (2018), 
confirmando ser uma ferramenta estimulante e acessível, adaptando-se a vários contextos escolares ou ao intercâmbio entre várias áreas do conhecimento.

Dentro da metodologia de teatro, os alunos devem ter à sua disposição, uma ampla gama de materiais para que possam explorar principalmente sua criatividade e capacidade de improvisação, haja vistas que o ambiente da sala de aula é bastante diferente do setor produtivo na área de avicultura, onde os mesmos realizam as aulas práticas. Neste sentido 97,1\% dos estudantes concordaram que todos os materiais disponibilizados haviam sido suficientes para um trabalho criativo e de boa qualidade. Deve-se destacar que a escola deve ter um inventário mínimo de materiais relacionados ao setor produtivo para disponibilizar aos estudantes e que não se deve tratar o empréstimo destes materiais de maneira burocrática, devendo-se trabalhar pela facilitação do processo.

No dia marcado para encenação, foi nítido o interesse dos estudantes pela apresentação de seus colegas, havendo momentos de grande descontração. Neste sentido, $97,1 \%$ dos estudantes relataram interesse nas apresentações dos colegas, sendo isso fundamental também para fortalecimento do relacionamento e amizade entre os mesmos. Este tipo de relação interaprendiz é um recurso valioso e essencial para o aprendizado e educação, colaborando muito para desenvolvimento de valores e virtudes (Moore, 2014).

Um aspecto negativo apontado pelos estudantes foi a baixa nota atribuída ao trabalho ( $4 \%$ da nota total distribuída na parte de avicultura), a qual pode ter colaborado para que uma média de 40,0\% dos estudantes não apresentasse na data marcada. Parte dos estudantes acredita que a nota é o fator mais importante no processo de ensino, corroborando com a ideia de que a maior parte dos estudantes brasileiros "estudam pra passar". De qualquer forma, 47,1\% demonstraram algum tipo de descontentamento com o valor de dois pontos. Por se tratar de uma atividade de extrema importância para a formação dos alunos, pode se recomendar que a nota atribuída a este trabalho seja de pelo menos $10 \%$ do valor total distribuído dentro da disciplina.

Dentro das novas ideias de educação na sociedade 4.0, a cooperação mútua é um requisito fundamental a ser trabalhado nos estudantes. Nota-se que a maior parte $(52,9 \%)$ dos estudantes marcaram a opção "equilibramos bem a divisão de tarefas e assim cada um fez a sua parte", sendo este aspecto positivo. Mesmo assim, 41,1\% apontaram algum tipo de desequilíbrio, sugerindo que alguns trabalharam mais do que outros. Neste sentido se deve destacar aqui que são jovens ainda em formação, onde parte não se despertou ainda para a necessidade de colaborar integralmente com os colegas, além de uma maior deficiência para administrar eficientemente inúmeras atividades e disciplinas que lhes foram atribuídas no primeiro ano do curso técnico. Houve também um estudante $(2,9 \%)$ que relatou ter feito o trabalho sozinho, sendo este um extremo preocupante, mas que pode acontecer em diferentes tipos de atividades acadêmicas.

\section{(ii) Percepção da atividade com base nas notas e observações pessoais}

Como comentado anteriormente, o objetivo maior na aplicação deste trabalho não foi somente a disponibilização e memorização de conhecimentos técnicos e acadêmicos. Os principais objetivos estão relacionados ao desenvolvimento de virtudes diversas relacionadas ao desenvolvimento humano dos estudantes. A partir das respostas foi possível se obter médias para cada uma das virtudes (Tabela 1). 
Tabela 1. Grau de percepção dos estudantes sobre o desenvolvimento de virtudes durante toda a metodologia do teatro na avicultura

\begin{tabular}{lccccc}
\hline & \multicolumn{5}{c}{ Virtude } \\
\cline { 2 - 6 } & Criatividade & Cooperação & Paciência & Proatividade & Resiliência \\
\hline Valor (entre 1 e 5)* & 4,09 & 4,09 & 3,14 & 4,06 & 3,79 \\
\hline
\end{tabular}

*Dados médios obtidos a partir da resposta de 34 estudantes. Fonte: Autores.

O desenvolvimento de virtudes e valores é essencial para a formação dos indivíduos e os professores devem ser exemplo e dar sua parcela de contribuição para que os estudantes tenham oportunidades para desenvolvimento (EcheverríaFalla, 2013; Jiménez e Raméntol, 2018). Nota-se que, de uma maneira geral, os estudantes reconhecem a importância do trabalho para o desenvolvimento de virtudes, principalmente criatividade, cooperação e proatividade, as quais alcançaram valores superiores a quatro. Todos estes valores ou virtudes são atualmente requisitos cruciais exigidos pelas empresas ou para sucesso dentro desta nova tendência empreendedora e são atualmente chamadas de "soft skills" ou ainda habilidades e competências.

A criatividade é uma das virtudes mais demandadas pela atual sociedade 4.0 e será no ambiente educacional que os sujeitos terão o maior número de possibilidades para desenvolvê-la. Todas as disciplinas, do nível fundamental a pósgraduação, necessitam proporcionar, mesmo que de maneira elementar, o desenvolvimento desta virtude. O professor deve se valer de ferramentas diversas para este fim. Também a cooperação é fundamental hoje para o cidadão. Seja como colaborador ou empreendedor, todos os sujeitos se relacionarão diretamente ou indiretamente, sendo crucial para o sucesso de suas atividades, bem como para promoção do diálogo e resolução de problemas diversos. Também a proatividade é atualmente demandada por todos os seguimentos da indústria, estando estritamente relacionada com a criatividade. Os novos profissionais demandados pela atual sociedade 4.0 devem apresentam bastante equilíbrio entre todas estas habilidades e competências (Zilli et al.. 2020).

A paciência pode ser considerada como a "mãe" de todas as outras virtudes, sendo fundamental que todos os sujeitos se relacionem harmonicamente numa sociedade com elevada diversidade cultural. Nota-se que foi aqui a virtude com menor peso atribuído pelos alunos. Provavelmente os mesmos não viram neste trabalho, uma oportunidade para aceitarem as falhas de seus colegas ou talvez as mesmas nem tenham ocorrido em uma magnitude necessária para essa percepção. A mesma situação pode também ter ocorrido para a resiliência, onde os estudantes podem não ter visto o trabalho como um problema de magnitude suficientemente grande para o desenvolvimento desta virtude. Nota-se que atualmente esta é, talvez, a principal virtude a ser trabalhada não somente no âmbito familiar, mas também no âmbito escolar, afim de preparar sujeitos que possam encarar com facilidade aos vários desafios que a vida lhes proporcionará.

\section{Conclusão}

A partir desta experiência se pode concluir que os estudantes aceitam bem a metodologia do teatro no curso técnico em Agropecuária e que essa contribui para desenvolvimento de virtudes, bem como para desinibição dos estudantes. Alguns ajustes são necessários, como uma maior pontuação a ser atribuída à atividade, bem como uma maior conscientização da importância da apresentação de todos os grupos visando um melhor aprendizado coletivo.

\section{Referências}

Albino, L. F. T., \& Tavernari, F. C. (2008). Produção e manejo de frangos de corte. Viçosa: UFV. 
Amorim K. P. C., Rocha A. K. C., Silva I. C. S., Melo L. M. B., \& Araújo M. A. A. (2015). Mediarte com amor e humor: uma experiência a partir do olhar dos participantes. Revista Brasileira de Educação Médica, 39 (2), 292-301. https://doi.org/10.1590/1981-52712015v39n2e01132014.

Bruner J. S. (1999). Para uma Teoria da Educação. Lisboa: Relógio D’Água.

Carvalho R. G., \& Novo R. F. (2014). The relationship between structural dimensions of personality and school life in adolescence. Psicologia: Reflexão $e$ crítica. 27(2), 376-388. 10.1590/1678-7153.201427218

Coelho M. A (2014). Teatro na escola: uma possibilidade de educação efetiva. Polêmica, 13 (2), 1-12. https://www.epublicacoes.uerj.br/index.php/polemica/article/view/10617/8513.

Costa Lins, M. J. S., \& Souza C. C. S. (2018). Avaliação do desenvolvimento da personalidade moral. Ensaio: Avaliação de Políticas Públicas em Educação, 26 (100), 1004-1020. https://doi.org/10.1590/s0104-40362018002601402.

Echeverría-Falla, C. (2013). Educación ética: ¿Normas o virtudes? ¿Qué giro debe tomar la enseñanza de la ética em la formación de universitarios solidarios? Persona y Bioética, 19(2) 151-167. https://www.redalyc.org/pdf/832/83230691002.pdf.

Francisco Junior W. E., Silva D. M., Nascimento R. C. F., \& Yamashita M. (2014). O teatro científico como ferramenta para a formação docente: uma pesquisa no âmbito do PIBID. Revista Brasileira de Pesquisa em Educação em Ciências, 14 (3) 79-100. https://periodicos.ufmg.br/index.php/rbpec/article/download/4294/2859/.

Freitas N. M. S., \& Gonçalves T. V. O. (2018). Práticas teatrais e o ensino de ciências: o teatro jornal na abordagem da temática do lixo. Educar em revista, 34 (68), 199-216. https://www.scielo.br/pdf/er/v34n68/0104-4060-er-34-68-199.pdf

Fuhr I. L. (2020). O professor e sua responsabilidade na sociedade contemporânea. Fractal: Revista de Psicologia, 32, 199-203. https://doi.org/10.22409/19840292/v32_i-esp/38852

Gonçalves J. P., \& Sestari L. (2015). A timidez segundo a perspectiva dos alunos de educação de jovens e adultos. InterMeio: Revista do Programa de Pós Graduação em Educação, Campo Grande, 21 (41), 146-167, https://periodicos.ufms.br/index.php/intm/article/view/2336/1418.

Goulart I. B. (2009). Piaget: experiências básicas para utilização pelo professor. Vozes.

Graça M., \& Gonçalves M. (2014). Os contributos do teatro na educação de adolescentes. Saber \& Educar, 19 (1), 22-73. http://revista.esepf.pt/index.php/sabereducar/article/download/83/51.

Hansted T. C., \& Gohn M. G. (2013). Teatro e educação: uma relação historicamente construída. EccoS Revista Científica, 30 (1), 199-220. http://periodicos.uninove.br/index.php?journal=eccos\&page=article\&op=viewFile \&path[]=3424\&path[]=2442

Instituto Brasileiro de Geografia e Estatística - IGBE (2016). Arranjos populacionais e concentrações urbanas no Brasil. (2a ed.), 167p. https://www.ibge.gov.br/apps/arranjos_populacionais/2015/pdf/publicacao.pdf

Jiménez G. G., \& Raméntol S. V. (2019). El valor o la virtude en la educación. Vivat Academia Revista de Comunicación, 145 (1), 23-39. http://www.vivatacademia.net/index.php/vivat/article/view/1075/1436.

Junqueira L. H., Silva E., \& Leitão L. A. (2002). O teatro na escola: uma proposta multidisciplinar no processo de ensino e aprendizagem nas aulas de Educação Física. Revista Digital, 8 (50). https://www.efdeportes.com/efd50/teatro.htm.

Marques, E. F. (2011) A utilização da avaliação tipo "teste” on-line como apoio ao ensino presencial: uma abordagem quantitativa sobre a sua contribuição no ensino de ferramentas estatísticas multivariadas. Avaliação: Revista da Avaliação da Educação Superior, 16 (2), https://www.scielo.br/pdf/aval/v16n2/a09v16n2.pdf

Martínez-Priego, C., Anaya-Hamue M. E. A., \& Salgado D. (2014) Desarrollo de la personalidad y virtudes sociales: relaciones en el contexto educativo familiar. Educación y Educadores, 7 (3), 447-467. http://dx.doi.org/10.5294/edu.2014.17.3.3

Moore M. G. (2014). Três tipos de interação. Dossies Tecoogs. n. 9, 73-80. https://www.pucsp.br/pos/tidd/teccogs/dossies/2014/edicao_9/1tres_tipos_interacao_american_journal_distance_education-three_types_of_interaction-michael_moore.pdf

Moraes D. A. F., \& Lima C. M. (2019). Os artefatos digitais como ferramentas mediadoras das atividades cognitivas dos estudantes: possibilidades para novos cenários de aprendizagem. Educar em Revista, 35 (1), 243-262. https://doi.org/10.1590/0104-4060.59642.

Oliveira, L. C., Costa A. T., Ponte M. L., Carvalho M. N., Silva Junior S. C., \& Melo S. P. (2020). A eficácia do body painting no ensino-aprendizagem da anatomia: um estudo randomizado. Revista Brasileira de Educação Médica, 44(2), 1-9. https://doi.org/10.1590/1981-5271v44.2-20190162

Sanfelice D., \& Meinerz A. (2017). O teatro como ferramenta pedagógica no ensino técnico integrado ao médio: uma experiência no IFRS campus Osório. Tear: Revista de Educação Ciência e Tecnologia, 6 (2), 1-13. https://doi.org/10.35819/tear.v6.n2.a2061

Silva Júnior A. D., Silveira R. D. D., \& Ferreira P. G. C. (2018). O teatro como ferramenta de ensino e aprendizagem no ensino médio: uma análise das escolas públicas de Urutaí e Pires do Rio. Multi-Science Journal, 1 (10), 12-20. http://dx.doi.org/10.33837/msj.v1i10.529

Vigotski L. S. (2001) Psicologia da arte. Martins Fontes

Welter R. B., Foletto D. S., \& Bortoluzzi V. I. (2019). Metodologias ativas: uma possibilidade para o multiletramento dos estudantes. Research, Society and Development, 9(1), 1-21. DOI: http://dx.doi.org/10.33448/rsd-v9i1.1664

Zilli J. C., Leopoldo A. L. S., Freire P. S., Vieira A. C. P., \& Boiani E. (2020). Competências e habilidades da indústria 4.0 no contexto dos cursos de administração e comércio exterior. $P 2 P$ \& Inovação, 7(1), 50-59. https://doi.org/10.21721/p2p.2020v7n1.pXXX-XXX 